\title{
The coxsackievirus and adenovirus receptor acts as a tumour suppressor in malignant glioma cells
}

\author{
M Kim', LA Sumerel', N Belousova', GR Lyons', DE Carey², V Krasnykh' and JT Douglas*,' \\ 'Division of Human Gene Therapy, Departments of Medicine, Pathology and Surgery, and the Gene Therapy Center, University of Alabama at \\ Birmingham, Birmingham, AL 35294, USA; ${ }^{2}$ Medical Statistics Section, Division of Hematology and Oncology, Department of Medicine, University of \\ Alabama at Birmingham, Birmingham, AL 35294, USA
}

\begin{abstract}
The coxsackievirus and adenovirus receptor (CAR) is a membrane glycoprotein with a cytoplasmic domain, a transmembrane domain and an extracellular region consisting of two immunoglobulin-like domains, an amino-terminal immunoglobulin variable (IgV)related domain (DI), which is distal to the cell surface, and a proximal IgC2 domain (D2). The coxsackievirus and adenovirus receptor has been shown to exhibit tumour suppression activity in human bladder and prostate cancer cells. In the current paper, we demonstrate that CAR is a tumour suppressor in glioma cells and that the extracellular D2 domain is not required for this inhibitory effect. This finding provides a biological basis for the observation that expression of CAR is downregulated in malignant glioma cells. This suggests that strategies to redirect adenoviruses to achieve CAR-independent infection will be necessary to realise the full potential of adenoviral vectors for cancer gene therapy.

British Journal of Cancer (2003) 88, I4I I-14 I6. doi: I0.1038/sj.bjc.6600932 www.bjcancer.com

(C) 2003 Cancer Research UK
\end{abstract}

Keywords: CAR; glioma; tumour suppressor

The first step in infection by many human adenoviruses, including the subgroup $C$ serotypes 2 and 5 most commonly used in gene therapy applications, is the high-affinity binding of the knob domain of the fibre protein (Henry et al, 1994; Louis et al, 1994) to the primary cellular receptor, the coxsackievirus and adenovirus receptor (CAR). The coxsackievirus and adenovirus receptor is a $46 \mathrm{kDa}$ class I membrane glycoprotein with a carboxy-terminal cytoplasmic domain, a transmembrane domain and an extracellular region consisting of two immunoglobulin-like domains, an amino-terminal immunoglobulin variable (IgV)-related domain (D1), which is distal to the cell surface, and a proximal IgC2 domain (D2). Although there is evidence for the evolutionary conservation of CAR, with homologues of the human receptor, hCAR, present in several mammalian species, including mice (Tomko et al, 1997; Bergelson et al, 1998), rats, dogs and pigs (Fechner et al, 1999) as well as in zebrafish (van Raaij et al, 2000), the normal physiological function of this membrane protein is unknown.

The identification of CAR as the primary adenovirus receptor triggered numerous studies demonstrating that primary cancer cells are frequently refractory to adenoviral infection because of a paucity of CAR on the cell surface (Dmitriev et al, 1998; Hemmi et al, 1998; Miller et al, 1998; Blackwell et al, 1999; Li et al, 1999; Vanderkwaak et al, 1999). More recently, it has been shown that the expression of CAR in highly tumorigenic CAR-deficient human prostate and bladder cancer cells leads to a growth-inhibitory

* Correspondence: Dr JT Douglas, Gene Therapy Center, University of Alabama at Birmingham, 901 19th Street South, BMR2 434, Birmingham, AL 35294, USA; E-mail: joanne.douglas@ccc.uab.edu

Received I November 2002; revised 30 January 2003; accepted 26 February 2003 effect (Okegawa et al, 2000, 2001). We have previously reported that the tumorigenic human U-118 MG glioblastoma cell line is refractory to adenoviral infection because of a paucity of CAR although it expresses the $\alpha_{\mathrm{v}}$ integrins necessary for virus internalisation (Miller et al, 1998). In the current study, we have tested the hypothesis that CAR serves as a tumour suppressor in this cell type. We also sought to determine which structural domains of CAR are responsible for its tumour-suppressive activity.

\section{MATERIALS AND METHODS}

\section{Construction of plasmids encoding mutant forms of CAR}

The $2.4 \mathrm{~kb}$ BamHI-NotI fragment carrying the hCAR cDNA was first subcloned from pcDNAI.hCAR (obtained from Robert W Finberg, Harvard Medical School, Boston, MA, USA) into the mammalian expression vector pcDNA3 (Invitrogen, Carlsbad, CA, USA) to give pcDNA3-hCAR. This plasmid was then used as template for PCR mutagenesis to construct the tailless hCAR truncation mutant by insertion of a stop codon after the position corresponding to amino-acid residue 260 (Wang and Bergelson, 1999). This construct therefore contained the extracellular domain, transmembrane domain and the first two amino acids from the cytoplasmic domain of hCAR. The hCAR-GPI construct was generated by overlap extension PCR to fuse the extracellular domain of hCAR (corresponding to amino-acid residues 1-235) to the 37 carboxy-terminal amino acids of human decay-accelerating factor (DAF) (Wang and Bergelson, 1999). The PCR products were inserted into the BamHI and Not s sites of pcDNA3 to give pcDNA3-hCAR-tailless and pcDNA3-hCAR-GPI, respectively. Deletion mutants of hCAR lacking the D1 or D2 extracellular 
domains (lacking amino acids 21-144 and 145-233, respectively (Freimuth et al, 1999)) were constructed by overlap extension PCR using pcDNA3-hCAR as the template. The PCR products were inserted into the $B a m \mathrm{HI}$ and NotI sites of pcDNA3 to give pcDNA3-hCAR $\triangle \mathrm{D} 1$ and $\mathrm{pcDNA3}-\mathrm{hCAR} \triangle \mathrm{D} 2$, respectively. The integrity of all constructs was verified by DNA sequencing using the CEQ2000XL DNA analysis system (Beckman-Coulter, Fullerton, CA, USA).

\section{Cell culture}

CAR-positive 293 cells (Graham et al, 1977) were purchased from Microbix (Toronto, Ontario, Canada) and CAR-negative human U-118 MG glioma cells were obtained from the American Type Culture Collection (Manassas, VA, USA). The cells were propagated at $37^{\circ} \mathrm{C}$ in a $5 \% \mathrm{CO}_{2}$ atmosphere in 50:50 mixture of Dulbecco's modified Eagle's medium and Ham's F-12 medium (DMEM/F-12), supplemented with $10 \%\left(\mathrm{vv}^{-1}\right)$ fetal calf serum (FCS), L-glutamine $(2 \mathrm{mM})$, penicillin $\left(100 \mathrm{U} \mathrm{ml}^{-1}\right)$ and streptomycin $\left(100 \mu \mathrm{g} \mathrm{ml}^{-1}\right)$. Stable transfectants were maintained in $400 \mu \mathrm{g} \mathrm{ml}^{-1}$ G418. FCS was purchased from Gibco-BRL (Grand Island, NY, USA), and media and supplements were from Mediatech (Herndon, VA, USA).

\section{Transfection of U-118 MG cells and selection of stable clones}

U-118 MG cells were transfected with the plasmids encoding hCAR or the hCAR deletion mutants using Superfect (Qiagen, Valencia, CA, USA) according to the manufacturer's protocol. Cells stably expressing hCAR or the hCAR deletion mutants were selected in the presence of G418 at a concentration of $400 \mu \mathrm{g} \mathrm{ml}^{-1}$.

Flow cytometry Confluent cells were released with Versene and resuspended in phosphate-buffered saline (PBS; Mediatech) containing $1 \%$ bovine serum albumin (BSA; Boehringer Mannheim, Indianapolis, IN, USA) at a concentration of $1-2 \times 10^{6}$ cells per $\mathrm{ml}$. One hundred microliters of cells $\left(1-2 \times 10^{5}\right)$ were incubated with $100 \mu \mathrm{l}$ of anti-hCAR monoclonal antibody RmcB at a concentration of $10 \mu \mathrm{g} \mathrm{ml}^{-1}$ for $1 \mathrm{~h}$ at $4^{\circ} \mathrm{C}$ with constant shaking. Cells were then washed with PBS containing 1\% BSA and incubated with $100 \mu \mathrm{l}$ of fluorescein isothiocyanate (FITC)-labelled rabbit anti-mouse IgG, Fc-specific secondary antibody (Jackson Immunoresearch Laboratories, West Grove, PA, USA) at a concentration of $10 \mu \mathrm{l} \mathrm{ml}^{-1}$ for $1 \mathrm{~h}$ at $4{ }^{\circ} \mathrm{C}$ with constant shaking. Cells were washed with PBS containing $1 \%$ BSA and fixed to a final volume of $300 \mu \mathrm{l}$ of $1-2 \%$ paraformaldehyde. Samples were then analysed by flow cytometry in the University of Alabama FACS Core Facility on an FACSCalibur machine using Cell quest FACS analysis software (Becton-Dickinson, Franklin Lakes, NJ, USA).

\section{Adenoviral vectors}

Ad5Luc1 is a first generation, E1-, E3-deleted Ad5 vector, which expresses firefly luciferase under the control of the cytomegalovirus (CMV) immediate-early promoter (Krasnykh et al, 2001). The recombinant adenoviral vectors were propagated on the permissive 293 cell line, purified by two rounds of cesium chloride density centrifugation and plaque titred on 293 cells according to standard techniques (Anon, 1998).

\section{Adenovirus-mediated reporter gene transfer assays}

In experiments to assay adenovirus-mediated luciferase gene delivery, $70 \%$ confluent U-118 MG cells or the stable transfectants in a 24-well tray were infected at a multiplicity of infection (MOI) of 100 plaque-forming units (PFU) per cell by adding Ad5Luc1 diluted in $100 \mu \mathrm{l}$ DMEM+2\% FCS and incubating for $30 \mathrm{~min}$ at room temperature. The unbound virus was then aspirated and the cells were washed with DMEM $+2 \%$ FCS and incubated in $100 \mu \mathrm{l}$ DMEM $+2 \%$ FCS for $1 \mathrm{~h}$ at $37^{\circ} \mathrm{C}$. One hundred microlitres of DMEM $+10 \%$ FCS were then added and the cells were incubated at $37^{\circ} \mathrm{C}$ for a further $24 \mathrm{~h}$ to allow luciferase expression. The cells were then lysed and assayed for luciferase activity using a luciferase assay system (Promega, Madison, WI, USA) according to the manufacturer's protocol.

\section{In vitro soft agar colony-formation assay}

U-118 MG cells were transfected with the various hCAR expression vectors and stable transfectants selected in the presence of $400 \mu \mathrm{g} \mathrm{ml}^{-1} \mathrm{G} 418$. Monolayers of cells were released with Versene and dispersed into a suspension of single cells in growth medium. One thousand cells were resuspended in $2 \mathrm{ml}$ of growth medium containing $0.4 \%$ low melting temperature agarose (Sea Plaque; FMC Products) and $400 \mu \mathrm{g} \mathrm{ml}^{-1} \mathrm{G} 418$, and were overlaid in triplicate on $2 \mathrm{ml}$ of solidified $0.8 \%$ low melting temperature agarose in growth medium in a 6-well dish. The dishes were incubated for 18 days at $37^{\circ} \mathrm{C}$ in a $5 \% \mathrm{CO}_{2}$ atmosphere. Colonies larger than 50 cells were then counted. Descriptive statistics (mean and standard deviation) on colony sizes were calculated. The mean colony sizes \pm standard deviations are shown. Statistical analysis was performed using one-way ANOVA. $P<0.05$ was considered statistically significant. All statistical tests were performed with Statistical Analysis Software (Version 6.12; SAS Institute, Inc., Cary, NC, USA).

\section{In vivo tumorigenicity assay}

Tumour xenografts were established by subcutaneous injection of $5 \times 10^{6} \mathrm{U}-118 \mathrm{MG}$ cells or the stably transfected derivatives into the flank of 8 - to 10 -week-old female athymic nude mice (nine or 10 mice per group) (nu/nu; Frederick Cancer Center, Frederick, MD, USA). Bidimensional tumour measurements were taken with calipers and the tumour volume was calculated using the simplified formula for a rotational ellipsoid: $0.5 \times$ length $\times$ width $^{2}$ (Dethlefsen et al, 1968). Statistical analysis was performed by oneway ANOVA using SAS. $P<0.05$ was considered statistically significant.

\section{RESULTS}

We first constructed two previously described truncation mutant forms of hCAR-tailless hCAR, containing the extracellular domain, transmembrane domain and the first two amino acids from the cytoplasmic domain of hCAR, and glycosylphosphatidyl (GPI)-anchored hCAR, lacking both the transmembrane and cytoplasmic domains (Figure 1) (Wang and Bergelson, 1999). The hCAR cDNA was first subcloned into the mammalian expression vector pcDNA3 to give pcDNA3-hCAR. This plasmid was then used as template for PCR mutagenesis to construct the tailless hCAR truncation mutant by insertion of a stop codon after the position corresponding to amino-acid residue 260 (Wang and Bergelson, 1999). The CAR-GPI construct was generated by overlap extension PCR to fuse the extracellular domain of hCAR (corresponding to amino-acid residues $1-235$ ) to the 37 carboxyterminal amino acids of human decay-accelerating factor (DAF) (Wang and Bergelson, 1999). The PCR products were inserted into pcDNA3 to give pcDNA3-hCAR-tailless and pcDNA3-hCAR-GPI, respectively. The integrity of the constructs was verified by DNA sequencing.

Monolayers of CAR-negative human U-118 MG malignant glioma cells were stably transfected with pcDNA3-hCAR, pcDNA3-hCAR-tailless, pcDNA3-hCAR-GPI or with the parental pcDNA3 plasmid as a control. Individual single-cell clones were 


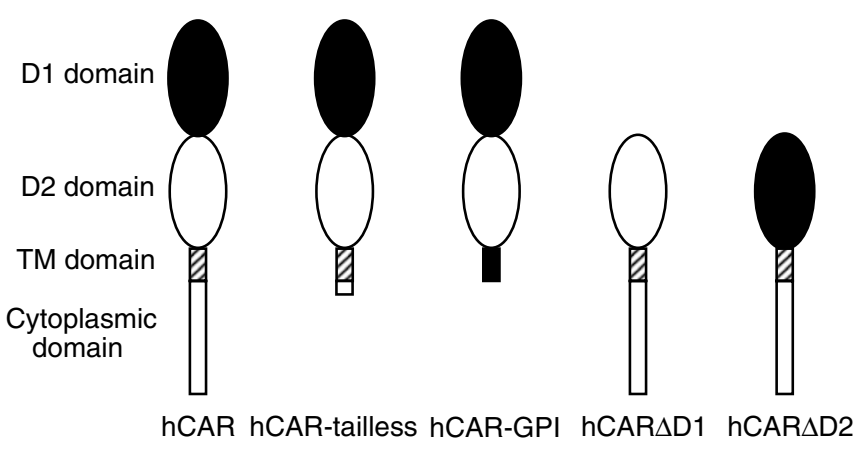

Figure I Schematic diagram of hCAR and deletion mutants. The coxsackievirus and adenovirus receptor comprises an extracellular region, a transmembrane domain (hatched rectangle) and a cytoplasmic domain (open rectangle). The extracellular region of wild-type CAR comprises an amino-terminal IgV-related domain designated DI (solid oval), which is distal to the cell surface, and a proximal IgC2 domain designated D2 (open oval). The hCAR-tailless mutant is truncated after amino acid 260. The hCAR-GPI mutant consists of the extracellular domain of hCAR (corresponding to amino-acid residues I-235) fused to the 37 carboxyterminal amino acids of human DAF. The hCAR $\Delta \mathrm{D}$ I mutant lacks amino acids $21-\mid 44$, while the hCAR $\Delta \mathrm{D} 2$ mutant lacks amino acids |45-233 (Freimuth et al, 1999).

isolated and expanded by selection in the presence of $400 \mu \mathrm{g} \mathrm{ml}^{-1}$ G418. Clones expressing equivalent levels of hCAR and the truncation mutants were identified on the basis of their susceptibility to infection by Ad5Luc1 (Krasnykh et al, 2001), an E1-deleted Ad5 vector which expresses the luciferase reporter gene under the control of the CMV promoter (data not shown). Expression of hCAR and the truncation mutants on the surface of the cells was confirmed by fluorescence-activated cell sorting (FACS) analysis using anti-hCAR monoclonal antibody $\mathrm{RmcB}$, which verified that the selected clones represented pure populations of stably transfected cells (Figure 2).

Tumour xenografts were established by subcutaneous injection of $5 \times 10^{6} \mathrm{U}-118 \mathrm{MG}$ cells or the stably transfected derivatives into the flank of 8 - to 10 -week-old female athymic nude mice (nine mice per group). Bidimensional tumour measurements were taken with calipers and the tumour volume was calculated. The mean tumour volumes on days 14 and 21 are shown in Figure 3. As expected, stable transfection of the U-118 MG cells with the parental pcDNA3 vector did not inhibit the growth of the subcutaneous tumors $(P>0.05$ on days 14 and 21$)$. However, the U-118 MG cells stably transfected with hCAR showed a significant decrease in tumorigenicity relative to the parental cells ( $P<0.05$ on days 14 and 21 , respectively). The U-118 MG cells stably transfected with hCAR-tailless likewise showed a significant decrease in tumorigenicity relative to the parental cells $(P<0.01$ on day $14 ; P<0.05$ on day 21), whereas no inhibition in tumour growth was observed with the cells stably transfected with hCARGPI ( $P>0.05$ on days 14 and 21). These findings are in accordance with earlier reports that the extracellular and transmembrane domains of hCAR, together with the first two amino acids of the cytoplasmic domain, are required for its biological activity in suppressing growth in human prostate and bladder cancer cells (Okegawa et al, 2000, 2001).

We then sought to examine the role of the extracellular domains of hCAR in the tumour-suppressive activity. Deletion mutants of hCAR (Figure 1) lacking the D1 or D2 extracellular domains (lacking amino acids 21-144 and 145-233, respectively (Freimuth et al, 1999)) were constructed by overlap extension PCR using pcDNA3-hCAR as the template. The PCR products were subcloned into pcDNA3 to give pcDNA3-hCAR $\Delta \mathrm{D} 1$ and pcDNA3-hCAR $\Delta \mathrm{D} 2$, respectively. The integrity of the constructs was verified by DNA sequencing.

We first investigated the ability of the deletion mutants to function as primary cellular receptors for human adenovirus serotype 5 (Ad5). Monolayers of U-118 MG malignant glioma cells were transiently transfected with pcDNA3-hCAR, pcDNA3hCAR $\triangle \mathrm{D} 1$ and $\mathrm{pcDNA3-hCAR} \Delta \mathrm{D} 2$. Forty-eight hours post-transfection, the cells were infected at a multiplicity of infection of 100 plaque-forming units per cell with Ad5Luc1. The cells were incubated for a further $24 \mathrm{~h}$ and the luciferase activity was determined. As shown in Figure 4, the parental U-118 MG cells were refractory to adenoviral infection, while expression of fulllength CAR rendered the U-118 MG cells susceptible to adenoviral infection. Luciferase expression in the cells transiently transfected with pcDNA3-hCAR $\triangle D 1$ was not enhanced over the parental cells, indicating that the hCAR deletion mutant lacking the membranedistal extracellular D1 domain was unable to mediate adenoviral
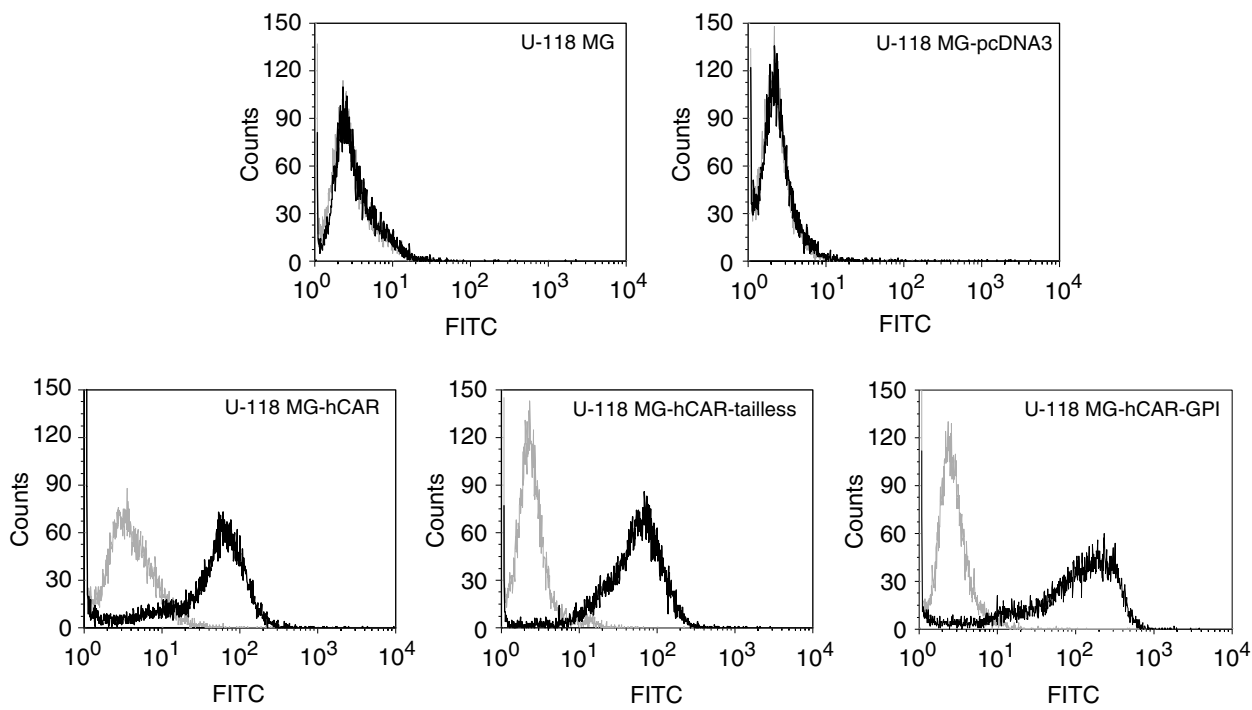

Figure 2 FACS analysis of stably transfected cells to confirm surface expression of hCAR and deletion mutants. Dark line is anti-hCAR primary monoclonal antibody RmcB plus FITC-labelled secondary antibody. Light line is FITC-labelled secondary antibody in the absence of primary antibody. 


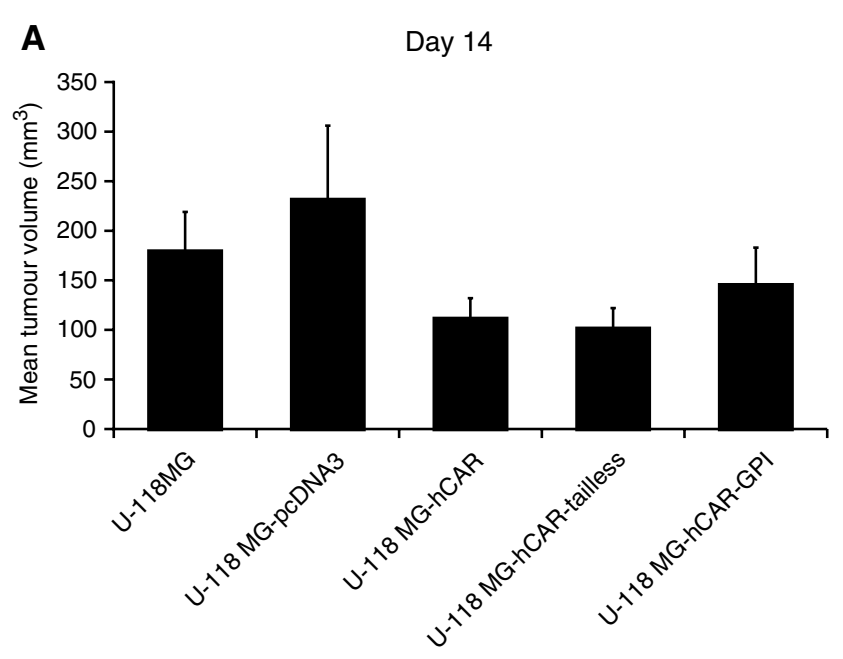

B

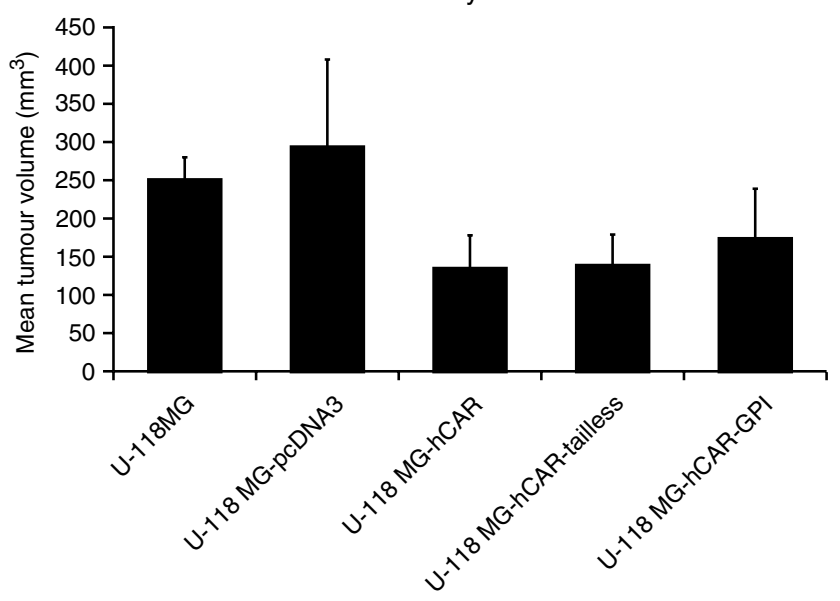

Figure 3 In vivo tumorigenicity assay. Tumour xenografts were established by subcutaneous injection of $5 \times 10^{6} \mathrm{U}-1 / 8 \mathrm{MG}$ cells or the stably transfected derivatives into the flank of 8- to I0-week-old female athymic nu/nu nude mice (nine mice per group). Bidimensional tumour measurements were taken with calipers and the tumour volume was calculated using the simplified formula for a rotational ellipsoid: $0.5 \times$ length $\times$ width $^{2}$ (Dethlefsen et al, 1968). The mean tumour volumes \pm standard deviations on days $14(\mathbf{A})$ and 21 (B) are shown. Statistical significance was achieved if $P<0.05$, based upon a one-way ANOVA.

infection. In contrast, luciferase activity could be detected in the cells transiently transfected with pcDNA3-hCAR $\triangle \mathrm{D} 2$, the plasmid expressing the hCAR deletion mutant lacking the extracellular D2 domain. This indicates that the membrane-displayed D1 domain of CAR was able to serve as a primary receptor for human adenovirus serotype 5. This observation is in accordance with previous studies which have shown that the isolated recombinant CAR D1 domain binds to the adenovirus fibre knob (Freimuth et al, 1999).

U-118 MG cells were then stably transfected with the various hCAR expression vectors and individual single-cell clones were isolated and expanded by selection in the presence of $400 \mu \mathrm{g} \mathrm{ml}^{-1}$ G418. Real-time quantitative RT-PCR and immunoblot analysis employing anti-hCAR monoclonal antibodies was performed in an attempt to choose clones expressing equivalent levels of hCAR, hCAR $\triangle \mathrm{D} 1$, and hCAR $\triangle \mathrm{D} 2$ mRNA and protein. The specificity of these assays for hCAR was assured by employing hCAR-positive 293 cells and hCAR-negative U-118 MG cells

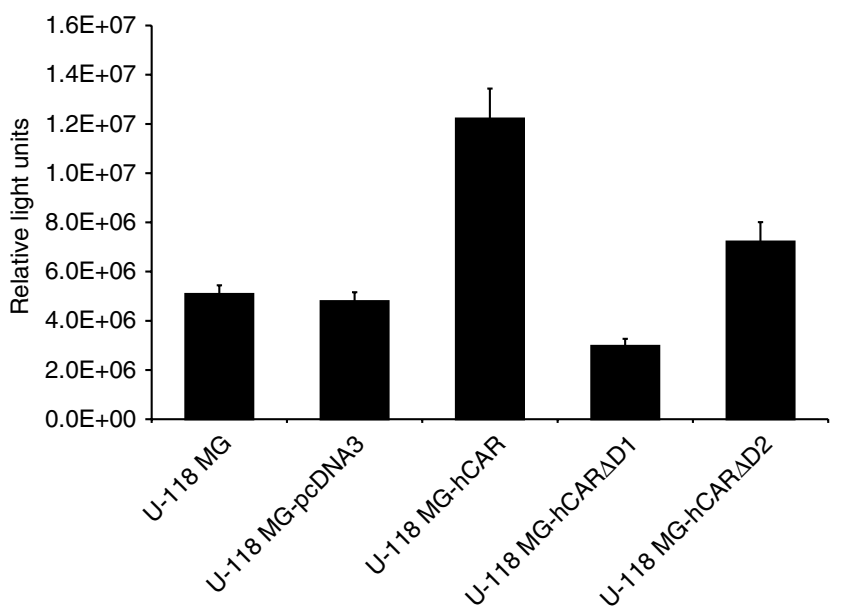

Figure 4 Adenovirus-mediated gene transfer to $\mathrm{U}$-II8 $\mathrm{MG}$ and derivative cells. Monolayers of CAR-negative human U- I 8 MG malignant glioma cells were transiently transfected with pcDNA3-hCAR, pcDNA3hCAR $\Delta \mathrm{DI}$ and pcDNA3-hCAR $\Delta \mathrm{D} 2$. Forty-eight hours post-transfection, the cells were infected at a multiplicity of infection of 100 p.f.u. per cell with Ad5Lucl. After incubation for I h at $37^{\circ} \mathrm{C}$, the vector was aspirated and the cells incubated at $37^{\circ} \mathrm{C}$ for $24 \mathrm{~h}$. The cells were then lysed and assayed for luciferase activity, which is expressed as relative light units. Data are reported as the means \pm standard deviations of triplicate determinations from a representative of three independent experiments. $P<0.05$ was considered statistically significant.

as controls. We were able to identify clones expressing approximately the same amounts of hCAR and hCAR $\triangle \mathrm{D} 2$, as determined from the respective mRNA and protein levels (data not shown). However, in spite of multiple attempts, we were unable to isolate a clone in which the level of hCAR $\triangle \mathrm{D} 1 \mathrm{mRNA}$ or protein was greater than $10 \%$ of the level achievable with hCAR or hCAR $\triangle \mathrm{D} 2$ (data not shown).

Tumour xenografts were again established by subcutaneous injection of $5 \times 10^{6} \mathrm{U}-118 \mathrm{MG}$ cells or the stably transfected derivatives into the flank of 8 - to 10 -week-old female athymic nude mice (10 mice per group). The mean tumour volumes on days 14 and 21 are shown in Figure 5. The U-118 MG cells stably transfected with hCAR showed a significant decrease in tumorigenicity relative to the parental cells $(P<0.05$ on day $14 ; P<0.01$ on day 21). Expression of hCAR $\triangle D 2$ also resulted in a significant inhibitory effect on the growth of the U-118 MG tumours $(P<0.05$ on days 14 and 21, respectively). Moreover, the size of the U-118 MG-hCAR $\triangle \mathrm{D} 2$ tumours was not significantly different from that of the U-118 MG-hCAR tumours $(P>0.05$ on days 14 and 21, respectively). These results therefore indicate that the expression of hCAR or hCAR $\triangle \mathrm{D} 2$ inhibits the tumorigenicity of U-118 MG glioma cells in vivo. In contrast, expression of hCAR $\triangle \mathrm{D} 1$ did not have a tumour-suppressive effect: the U-118 MG-hCAR $\Delta D 1$ tumours were not significantly different in size from the parental U-118 MG tumours ( $P>0.05$ on days 14 and 21$)$, although this could have been due to the low level of expression of hCAR $\triangle D 1$ in the stably transfected U-118 MG cells.

In order to rule out the possibility of the tumour-suppressive activity observed in vivo being due to a clonal effect, U-118 MG cells were again transfected with pcDNA3-hCAR, pcDNA3hCAR $\triangle D 1$ or pcDNA3-hCAR $\triangle D 2$ and stable transfectants selected in the presence of $400 \mu \mathrm{g} \mathrm{ml}^{-1} \mathrm{G} 418$. The tumorigenicity of the parental U118-MG cells and pooled clones of the derivative cell lines was determined in vitro in a soft agar colony-formation assay. Monolayers of cells were released with Versene and dispersed into a suspension of single cells. One thousand cells were resuspended in $2 \mathrm{ml}$ of growth medium containing $0.4 \%$ low melting 
A

Day 14

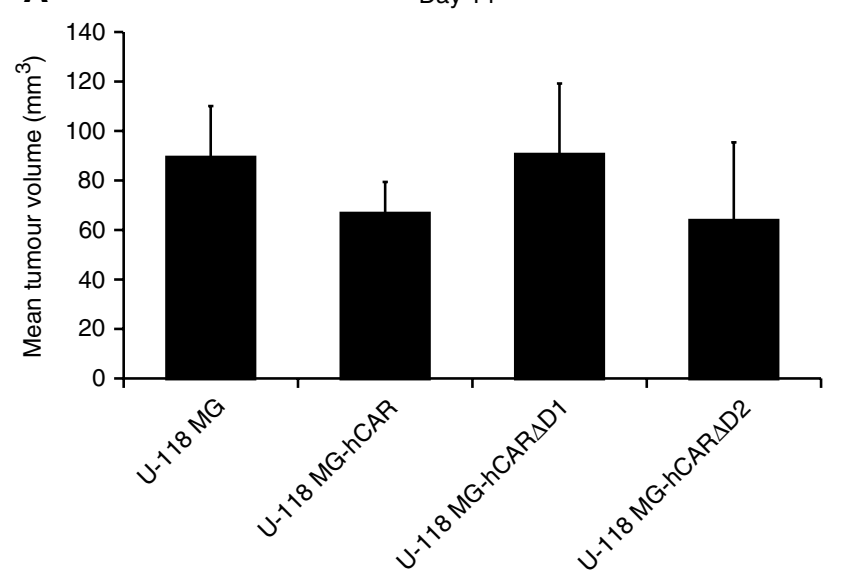

B

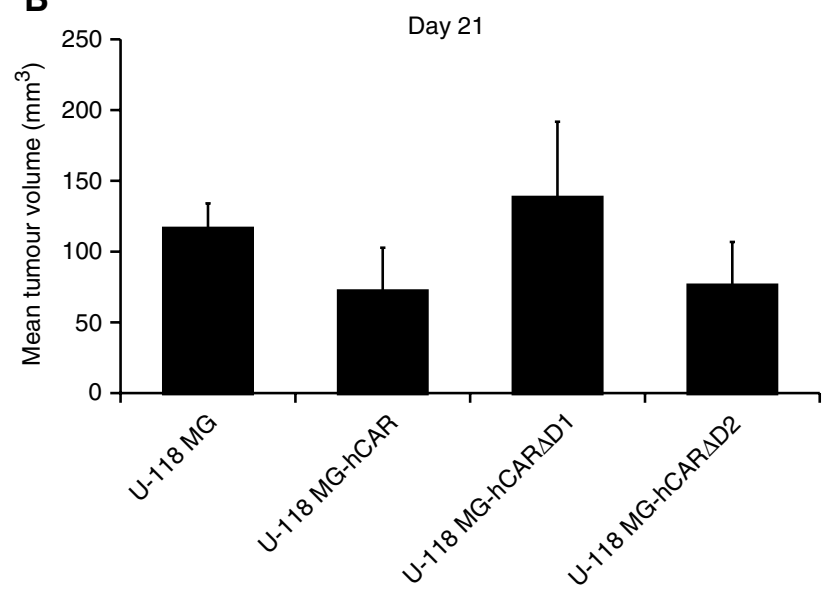

Figure 5 In vivo tumorigenicity assay. Tumour xenografts were established by subcutaneous injection of $5 \times 10^{6} \mathrm{U}-1$ I $8 \mathrm{MG}$ cells or the stably transfected derivatives into the flank of 8- to 10 -week-old female athymic nu/nu nude mice ( 10 mice per group). Bidimensional tumour measurements were taken with calipers and the tumour volume was calculated using the simplified formula for a rotational ellipsoid: $0.5 \times$ length $\times$ width $^{2}$ (Dethlefsen et al, 1968). The mean tumour volumes \pm standard deviations on days $14(\mathbf{A})$ and 21 (B) are shown. Statistical analysis was performed by one-way ANOVA. $P<0.05$ was considered statistically significant.

temperature agarose plus $400 \mu \mathrm{g} \mathrm{ml}^{-1} \mathrm{G} 418$ in the case of the transfected cells, and were overlaid in triplicate on $2 \mathrm{ml}$ of solidified $0.8 \%$ low melting temperature agarose in growth medium in a six-well dish. The dishes were incubated for 18 days at $37^{\circ} \mathrm{C}$ in a $5 \% \mathrm{CO}_{2}$ atmosphere. Colonies containing more than 50 cells were then counted.

As shown in Figure 6, expression of hCAR by U-118 MG cells caused a significant reduction in the number of colonies formed by the glioma cells in this assay $(P<0.05)$. The mean number of U-118 MG colonies was $149 \pm 32$, while the mean number of U-118 MG-hCAR colonies was $88 \pm 14$. The mean number of U-118 MG-hCAR $\Delta \mathrm{D} 2$ colonies was $78 \pm 5$, which was significantly less than the number of colonies formed by the parental U-118 MG cells $(P<0.05)$, but not significantly different from the number of U-118 MG-hCAR colonies $(P>0.05)$. The mean number of U-118 MG-hCAR $\Delta D 1$ colonies was $223 \pm 22$, which was significantly greater than the numbers of both U-118 MG-hCAR and U-118 MG-hCAR $\Delta$ D2

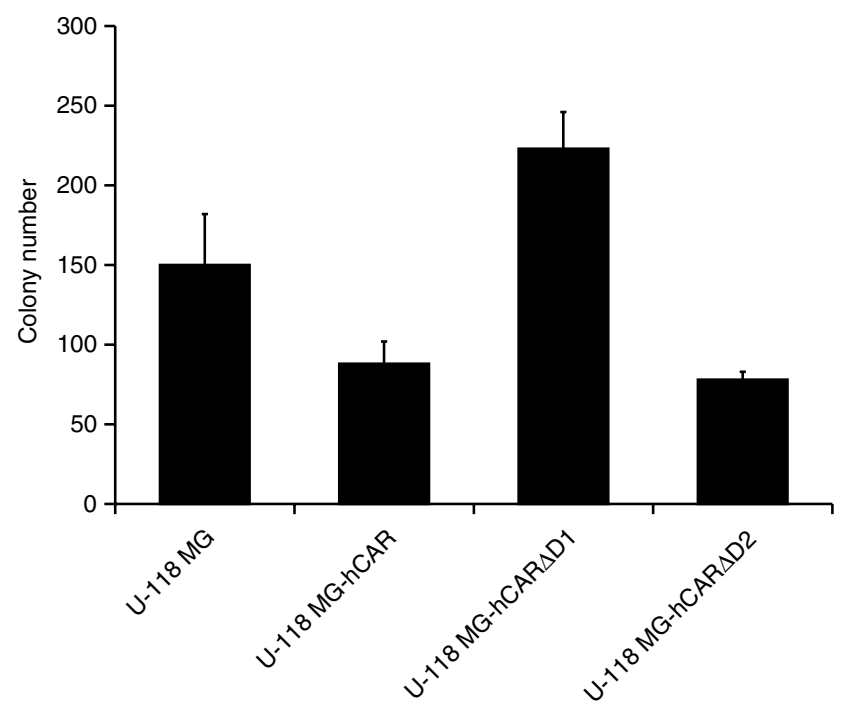

Figure 6 In vitro soft agar colony-formation assay. U- I I 8 MG cells were transfected with the various hCAR expression vectors and stable transfectants selected in the presence of $400 \mu \mathrm{g} \mathrm{ml}^{-1} \mathrm{G} 4$ I8. Monolayers of cells were released with Versene and dispersed into a suspension of single cells in growth medium. One thousand cells were resuspended in $2 \mathrm{ml}$ of growth medium containing $0.4 \%$ low melting temperature agarose (and $400 \mu \mathrm{g} \mathrm{ml}^{-1} \mathrm{G} 4 \mathrm{l} 8$ in the case of the transfectants), and were overlaid in triplicate on $2 \mathrm{ml}$ of solidified $0.8 \%$ low melting temperature agarose in growth medium in a 6-well dish. The dishes were incubated for 18 days at $37^{\circ} \mathrm{C}$ in a $5 \% \mathrm{CO}_{2}$ atmosphere. Colonies larger than 50 cells were then counted. The mean colony sizes + standard deviations are shown. Statistical analysis was performed by one-way ANOVA. $P<0.05$ was considered statistically significant.

colonies $(P<0.001$ in each case). The results of this soft agar colony-formation assay therefore indicate that expression of both hCAR and hCAR $\triangle \mathrm{D} 2$ results in a tumour-inhibitory effect in vitro, while expression of hCAR $\Delta \mathrm{D} 1$ does not suppress the growth of the glioma cells in vitro.

\section{DISCUSSION}

Previous reports have shown that the extracellular and transmembrane domains of hCAR, together with the first two amino acids of the cytoplasmic domain, are required for its biological activity in suppressing growth in human prostate and bladder cancer cells (Okegawa et al, 2000, 2001). We have extended those studies by showing that the extracellular D2 domain of hCAR is not required for CAR to function as a tumour suppressor.

Our findings demonstrate that CAR serves as a tumour suppressor in glioma cells both in vitro and in vivo. This provides a physiological explanation for the downregulation of CAR observed in malignant glioma cells (Miller et al, 1998), although the biological trigger underlying this step in the pathway of malignant transformation remains to be elucidated. Downregulation of CAR has similarly been observed in other tumour types, including ovarian cancer (Dmitriev et al, 1998), melanoma (Hemmi et al, 1998) and head and neck cancer (Dmitriev et al, 1998; Hemmi et al, 1998; Li et al, 1999). The level of expression of CAR mRNA in bladder cancer specimens from human patients has been shown to correlate inversely with the aggressiveness of the tumour: invasive bladder cancer specimens had significantly reduced CAR mRNA levels compared with superficial bladder cancer specimens (Okegawa et al, 2001). Similarly, when compared with normal prostate, CAR expression is decreased in prostate 
carcinoma specimens of all Gleason scores (Rauen et al, 2002). Conversely, metastatic prostate specimens express CAR (Rauen et al, 2002). These results suggest that strategies to redirect adenoviruses to achieve CAR-independent infection will be necessary to realise the full potential of adenoviral vectors for gene therapy of primary tumours in the clinical setting (Barnett et al, 2002).

\section{REFERENCES}

Anon (1998) Use and application of adenovirus expression vectors. In Cells: A Laboratory Manual, Leinwand LA (ed) Vol. 2, pp 90.1-90.28. New York: Cold Spring Harbor Laboratory Press

Barnett BG, Crews CJ, Douglas JT (2002) Targeted adenoviral vectors. Biochim Biophys Acta 1575: $1-14$

Bergelson JM, Krithivas A, Celi L, Droguett G, Horwitz MS, Wickham T, Crowell RL, Finberg RW (1998) The murine CAR homolog is a receptor for coxsackie B viruses and adenoviruses. J Virol 71: 415-419

Blackwell JL, Miller CR, Douglas JT, Li H, Reynolds PN, Carroll WR, Peters GE, Strong TV, Curiel DT (1999) Retargeting to EGFR enhances adenovirus infection of squamous cell carcinoma of the head and neck. Arch Otolaryngol Head Neck Surg 125: 856-863

Dethlefsen LA, Prewitt JM, Mendelsohn ML (1968) Analysis of tumor growth curves. J Natl Cancer Inst 40: 389-405

Dmitriev I, Krasnykh V, Miller CR, Wang M, Kashentseva E, Mikheeva G, Belousova N, Curiel DT (1998) An adenovirus vector with genetically modified fibers demonstrates expanded tropism via utilization of a coxsackievirus and adenovirus receptor-independent cell entry mechanism. J Virol 72: 9706-9713

Fechner H, Haack A, Wang H, Wang X, Eizema K, Pauschinger $M$, Schoemaker RG, van Veghel R, Houtsmuller AB, Schultheiss H-P, Lamers JMJ, Poller W (1999) Expression of coxsackie adenovirus receptor and alphav-integrin does not correlate with adenovector targeting in vivo indicating anatomical vector barriers. Gene Therapy 6: $1520-1535$

Freimuth P, Springer K, Berard C, Hainfeld J, Bewley M, Flanagan J (1999) Coxsackievirus and adenovirus receptor amino-terminal immunoglobulin V-related domain binds adenovirus type 2 and fiber knob from adenovirus type 12. J Virol 73: $1392-1398$

Graham F, Smiley J, Russell W, Nairn R (1977) Characteristics of a human cell line transformed by DNA from human adenovirus type 5. J Gen Virol 36: $59-72$

Hemmi S, Geertsen R, Mezzacasa A, Peter I, Dummer R (1998) The presence of human coxsackievirus and adenovirus receptor is associated with efficient adenovirus-mediated transgene expression in human melanoma cell cultures. Hum Gene Ther 9: 2363-2373

Henry LJ, Xia D, Wilke ME, Deisenhofer J, Gerard RD (1994) Characterization of the knob domain of the adenovirus type 5 fiber protein expressed in Escherichia coli. J Virol 68: 5239-5246

\section{ACKNOWLEDGEMENTS}

This work was supported by a grant from the Muscular Dystrophy Association, grant DOUGLA00I0 from the Cystic Fibrosis Foundation and NIH grant R03 AR46864.

Krasnykh V, Belousova N, Korokhov N, Mikheeva G, Curiel DT (2001) Genetic targeting of an adenovirus vector via replacement of the fiber protein with the phage T4 fibritin. J Virol 75: 4176-4183

Li D, Duan L, Freimuth P, O'Malley BWJ (1999) Variability of adenovirus receptor density influences gene transfer efficiency and therapeutic response in head and neck cancer. Clin Cancer Res 5: 4175-4181

Louis N, Fender P, Barge A, Kitts P, Chroboczek J (1994) Cell-binding domain of adenovirus serotype 2 fiber. J Virol 68: 4104-4106

Miller CR, Buchsbaum DJ, Reynolds PN, Douglas JT, Gillespie GY, Mayo MS, Raben D, Curiel DT (1998) Differential susceptibility of primary and established human glioma cells to adenovirus infection: targeting via the epidermal growth factor receptor achieves fiber receptor-independent gene transfer. Cancer Res 58: $5738-5748$

Okegawa T, Li Y, Pong RC, Bergelson JM, Zhou J, Hsieh JT (2000) The dual impact of coxsackie and adenovirus receptor expression on human prostate cancer gene therapy. Cancer Res 60: $5031-5036$

Okegawa T, Pong RC, Li Y, Bergelson JM, Sagalowsky AI, Hsieh JT (2001) The mechanism of the growth-inhibitory effect of coxsackie and adenovirus receptor (CAR) on human bladder cancer: a functional analysis of CAR protein structure. Cancer Res 61: 6592-6600

Rauen KA, Sudilovsky D, Le JL, Chew KL, Hann B, Weinberg V, Schmitt LD, McCormick F (2002) Expression of the coxsackie adenovirus receptor in normal prostate and in primary and metastatic prostate carcinoma: potential relevance to gene therapy. Cancer Res 62: $3812-3818$

Tomko RP, Xu R, Philipson L (1997) HCAR and MCAR: the human and mouse cellular receptors for subgroup $C$ adenoviruses and group $B$ coxsackieviruses. Proc Natl Acad Sci USA 94: 3352-3356

van Raaij MJ, Chouin E, van der Zandt H, Bergelson JM, Cusack S (2000) Dimeric structure of the coxsackievirus and adenovirus receptor D1 domain at 1.7 A resolution. Struct Fold Des 8: 1147-1155

Vanderkwaak TJ, Wang M, Gomez-Navarro J, Rancourt C, Dmitriev I, Krasnykh V, Barnes M, Siegal GP, Alvarez R, Curiel DT (1999) An advanced generation of adenoviral vectors selectively enhances gene transfer for ovarian cancer gene therapy approaches. Gynecol Oncol 74: $227-234$

Wang X, Bergelson JM (1999) Coxsackievirus and adenovirus receptor cytoplasmic and transmembrane domains are not essential for coxsackievirus and adenovirus infection. J Virol 73: 2559-2562 